\title{
Efficient Aerobic Oxidation of Cyclohexane to KA Oil Catalyzed by Pt-Sn supported on MWCNTs
}

\author{
MOHAMMAD SADIQ ${ }^{\mathrm{a}, *}$, MUHAMMAD ALI ${ }^{\mathrm{a}}$, RASHID IQBAL ${ }^{\mathrm{a}}$, KHALID SAEED $^{\mathrm{a}}$, \\ AIMAL KHAN $^{\mathrm{a}}$, MUHAMMAD NAVEED UMAR ${ }^{\mathrm{a}}$ and HAROON UR RASHID ${ }^{\mathrm{b}}$ \\ ${ }^{a}$ Department of Chemistry, University of Malakand, Chakdara, Dir (L), Khyber Pakhtunkhwa, Pakistan \\ ${ }^{b}$ Department of Chemistry, Sarhad University of Science and Information Technology, Peshawar, \\ Khyber Pakhtunkhwa, Pakistan \\ e-mail: mohammad_sadiq26@yahoo.com
}

MS received 27 July 2014; revised 04 March 2015; accepted 05 March 2015

\begin{abstract}
Pt-Sn supported on MWCNTs were synthesized and characterized by SEM, EDX, XRD, XRF and surface area and pore size analyzer. The catalyst was used for the partial oxidation of cyclohexane in a Parr type reactor. It was found that Pt-Sn supported on MWCNTs can act as an efficient catalyst for the partial oxidation of cyclohexane into cyclohexanol and cyclohexanone, generating both in a high yield under mild reaction conditions.
\end{abstract}

Keywords. Cyclohexane; oxidation; cyclohexanol; cyclohexanone.

\section{Introduction}

The selective oxidation of cyclohexane to KA oil (cyclohexanone and cyclohexanol) is a process of significant industrial importance because KA oil is used as a raw material for the manufacture of nylon 6 and nylon $6,6 .{ }^{1}$ Conventionally, the oxidation of cyclohexanol to KA oil is catalyzed by soluble cobalt or manganese salts where they act as homogeneous catalysts. The reaction is carried out at $140-180^{\circ} \mathrm{C}$ and $0.8-2 \mathrm{MPa}$ in air for $15-60 \mathrm{~min} .{ }^{1}$ This process gives $70-85 \%$ selectivity. However, the cyclohexane conversion ratio is usually limited to less than $6 \%$ to prevent further oxidation of the target KA-oil. A number of alternative processes that employ heterogeneous catalysts have been proposed for the selective cyclohexane conversion without a significant decrease in the selectivity for KA-oil. Catalysts consisting of gold nanoparticles supported on zeolites can convert cyclohexane to KA-oil at $150^{\circ} \mathrm{C}$ in a $1 \mathrm{MPa} ; \mathrm{O}_{2}$ atmosphere for $2-6 \mathrm{~h}$ with a $6-19 \%$ conversion ratio and $92-100 \%$ selectivity, in the absence of free-radical scavengers. ${ }^{2-4}$ Gold nanoparticles embedded in amorphous silica $\left(\mathrm{Au} / \mathrm{SiO}_{2}\right)$ has been reported as a catalyst for the conversion of cyclohexane with a high catalytic activity and selectivity of $22.7 \%$ and $80.6 \%$, respectively. However, the process requires toxic and explosive tert-butyl hydro peroxide (TBHP) as radical initiator. ${ }^{5}$ Size-controlled Au clusters on hydroxyapatite

\footnotetext{
*For correspondence
}

have exhibited a cyclohexane conversion ratio of 6.7$14.9 \%$ with an efficient selectivity for KA-oil at $150^{\circ} \mathrm{C}$ under $1 \mathrm{MPa} \mathrm{O}_{2}$ for $24 \mathrm{~h}$, but the addition of a small amount of TBHP is also essential in this case to initiate the reaction. ${ }^{6}$

Mesoporous chromium iron terepthalates have been demonstrated to efficiently catalyze the oxidation of cyclohexane. ${ }^{7}$ The Cr-MIL-101/TBHP system has been reported to produce KA oil with $92 \%$ selectivity at a $25 \%$ cyclohexane conversion ratio, while Fe-MIL$101 / \mathrm{TBHP} / \mathrm{O}_{2}$ has been reported to yield a mixture of cyclohexyl hydroperoxide, cyclohexanol and cyclohexanone with $99 \%$ total selectivity (49\% selectivity for KA-oil) and a conversion ratio of about $38 \%$ at $70^{\circ} \mathrm{C}$ in air $(1 \mathrm{~atm})$ in $8 \mathrm{~h}$. However, in this case too, the addition of TBHP is essential. Fe-filled carbon nanotubes have yielded a cyclohexane conversion ratio of about $37 \%$ at $125^{\circ} \mathrm{C}$ and $1.5 \mathrm{MPa} ; \mathrm{O}_{2}$ for $8 \mathrm{~h}$, but the selectivity for KA-oil was about $30 \%$ due to over-oxidation. ${ }^{8}$

This scenario has promoted to develop catalysts for the oxidation of cyclohexane that can generate high conversion ratio with high selectivity for KA oil in a liquid phase reaction. We have previously reported zirconia and zirconia supported noble metals as catalysts for the oxidation of cyclohexane under moderate conditions. ${ }^{9}$

In the current study, we have designed an advanced catalyst that is beautifully tailored for the oxidation of cyclohexane to KA-oil in the liquid phase without requiring radical initiators or free-radical scavengers. In this catalyst, platinum acts as the main oxidizing agent 
and $\mathrm{Sn}$ as a promoter to facilitate the oxidation reaction. Multi-walled carbon nanotubes (MWCNTs) have been used as a catalyst support instead of classical catalyst supports such as Silica/ $\gamma-\mathrm{Al}_{2} \mathrm{O}_{3}$ because it has superior adsorption capabilities for cyclohexane.

\section{Experimental}

\subsection{General}

Chemicals and reagents used in the study were supplied by Merck and Scharlau, and used without further purification. MWCNTs were provided by Tokyo Chemical Industry CO; LTD. Nitrogen, oxygen and hydrogen were supplied by BOC Pakistan limited. These gases were passed through appropriate filters (C.R.S.Inc.202 268 \& C.R.S.Inc.202223) for removal of water vapours and traces of oil.

\subsection{Preparation of the catalyst}

MWCNTs ( $1 \mathrm{~g}$ ) were functionalized by modified Hummer and Offeman's method and sonicated in $50 \mathrm{~mL}$ equimolar solution of $\mathrm{HNO}_{3}(5 \mathrm{M})$ and $\mathrm{H}_{2} \mathrm{SO}_{4}(5 \mathrm{M})$ in the presence of $\mathrm{KMnO}_{4}(6 \mathrm{~g})$ as an oxidant, for $30 \mathrm{~min}$ at $30^{\circ} \mathrm{C}$. The MWCNTs were then washed with hot double distilled water (total $4 \mathrm{~L}$ ) by centrifugation and decantation until the $\mathrm{pH}$ was nearly neutral. The sample was then filtered through a $0.2 \mu \mathrm{m}$ PTFE membrane. Finally it was washed with n-hexane and dried overnight under low pressure. In the next step, functionalized MWCNTs were treated with $500 \mathrm{~mL}$ solution of $\mathrm{SnCl}_{2}(11.3 \mathrm{~g})$ and $\mathrm{HCl}(13 \mathrm{~mL})$. The mixture was sonicated for $30 \mathrm{~min}$ and aged for $48 \mathrm{~h}$ at $25^{\circ} \mathrm{C}$. Then MWCNTs were separated by centrifugation and decantation and washed with double distilled water and n-hexane. Subsequently, the sample was treated with $500 \mathrm{~mL}$ solution of $\mathrm{PtCl}_{4}(0.25 \mathrm{~g})$ and $\mathrm{HCl}(13 \mathrm{~mL})$ and the mixture was sonicated for $30 \mathrm{~min}$ at room temperature. After sonication, the sample was separated from the mixture by centrifugation and washed with double distilled water and n-hexane and dried overnight under low pressure.

\subsection{Catalytic test}

As a catalytic test, oxidation of cyclohexane was carried out in a Parr type reactor. $10 \mathrm{~mL}$ cyclohexane and $50 \mathrm{mg}$ catalyst were loaded into the reactor. The reaction mixture was continuously stirred by magnetic stirrer. The temperature of the reaction mixture was controlled by Digi-Sense Temperature Controller R/S. The products were analyzed by GC equipped with FID (Clarus 580, PerkinElmer, USA) while turn over frequency (TOF) was calculated from the rate of KAoil synthesis divided by the number of $\mathrm{CO}$ molecules chemisorbed on the platinum surface.

\subsection{Characterization}

The sample composition was analyzed by X-ray fluorescence spectrometry (Rigaku ZSX-100e) on the basis of $\mathrm{CO}$ chemisorption, considering that platinum is a spherical particle and can adsorb only one molecule of CO. XRD of the catalyst was performed by X-ray diffractometer (Rigaku D/Max-II, Japan) using $\mathrm{Cu}-\mathrm{K} \alpha$ radiation $(40 \mathrm{kV}, 30 \mathrm{~mA})$. Surface morphology and elemental analysis was performed using SEM/EDX (JSM 5910, JEOL Japan). Surface area and pore size were measured by BET surface area analyzer (Quantachrome Nova 2200e, USA).

\section{Results and Discussion}

\subsection{Characterization}

Table 1 presents BET and BJH surface area, and plati num dispersion data for Pt-Sn/MWCNTs. According to the results obtained by the BJH technique, the pore volume was $0.27 \mathrm{cc} / \mathrm{g}$, the pore diameter was $35.7 \AA$ and surface area was $124.6 \mathrm{~m}^{2} / \mathrm{g}$. The surface area according to BET method was $136.2 \mathrm{~m}^{2} / \mathrm{g}$ which is in close agreement with the surface area obtained by BJH technique. Khedr et al. ${ }^{10}$ have reported a surface area of $109.5 \mathrm{~m}^{2} / \mathrm{g}$ for MWCNTs decorated with $\mathrm{CuFe}_{2} \mathrm{O}_{4}$. Hence, it can be asserted that our findings of the catalysts surface area are in agreement with the data reported in the literature.

Figure 1 shows SEM images of the catalyst which reveal that there are no noticeable differences between

Table 1. Surface characteristics of the catalyst used for the aerobic oxidation of cyclohexane.

\begin{tabular}{|c|c|c|c|c|c|c|c|c|c|}
\hline \multirow[b]{2}{*}{ Catalyst } & \multicolumn{2}{|c|}{$\begin{array}{c}\text { Surface area } \\
\left(\mathrm{m}^{2} \mathrm{~g}^{-1}\right)\end{array}$} & \multirow{2}{*}{$\begin{array}{c}\text { Dispersion } \\
(\%)\end{array}$} & \multirow{2}{*}{$\begin{array}{c}\text { Conv } \\
(\mathrm{mol} \%)\end{array}$} & \multirow{2}{*}{$\begin{array}{l}\text { KA-oil yield } \\
\left(10^{-2} \times \text { mol }\right)\end{array}$} & \multirow{2}{*}{$\begin{array}{c}\text { KA-oil syn rate } \\
\left(10^{-3} \times \mathrm{mol} \mathrm{g}^{-1} \mathrm{~h}^{-1}\right)\end{array}$} & \multicolumn{2}{|c|}{$\begin{array}{c}\text { Selectivity } \\
(\mathrm{mol} \%)\end{array}$} & \multirow{2}{*}{$\begin{array}{l}\text { TOF } \\
\left(\mathrm{h}^{-1}\right)\end{array}$} \\
\hline & BET & $\mathrm{BJH}$ & & & & & nol & none & \\
\hline Pt- Sn/ MWCNTs & 136.2 & 124.6 & 22.2 & 15.0 & 2.32 & 7.70 & 55.2 & 28.2 & 2987.1 \\
\hline
\end{tabular}



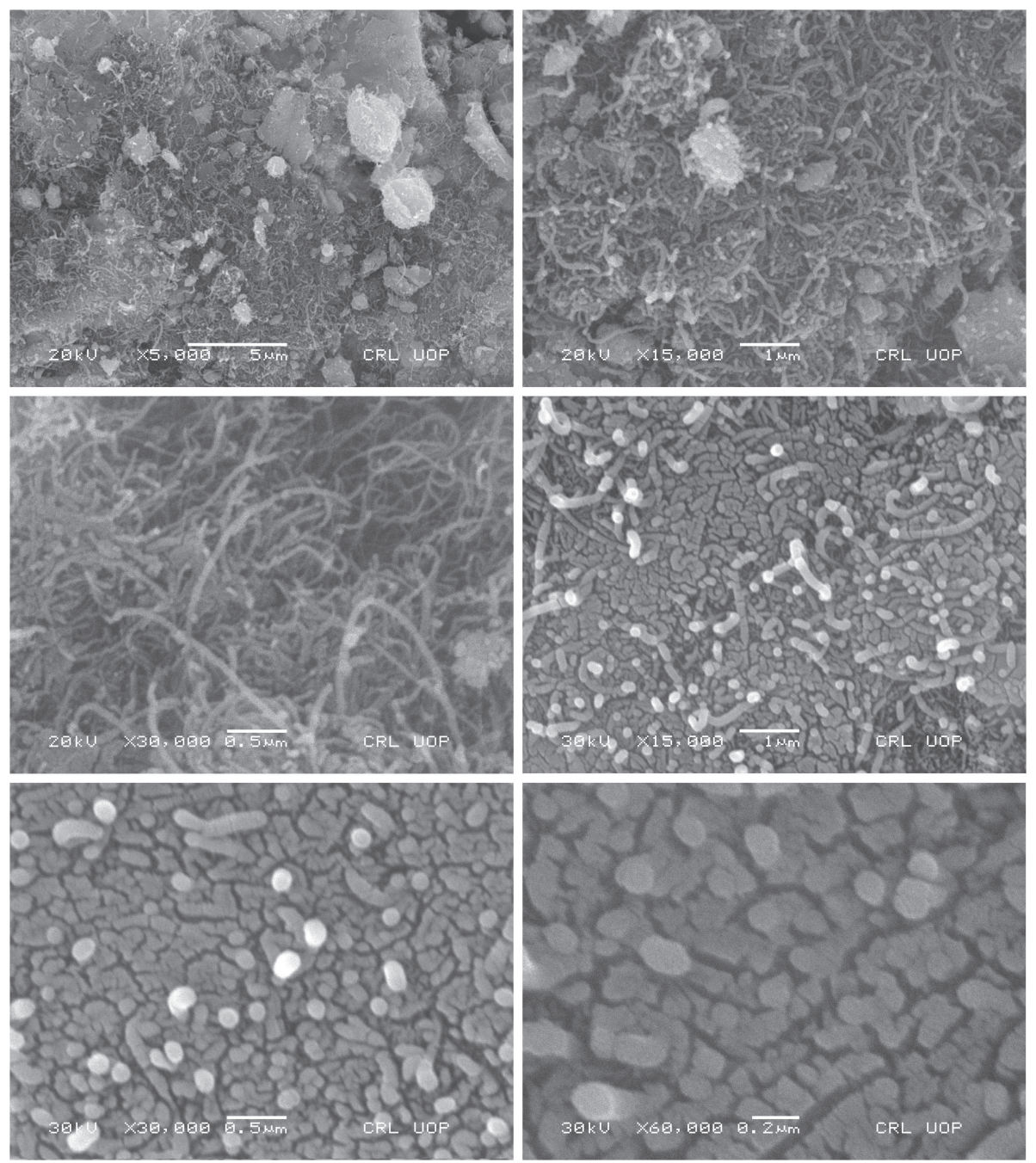

Figure 1. SEM images of Pt-Sn/MWCNTs at different magnifications with and without dispersion, respectively.

the Pt spot and Sn spot on the surface of MWCNTs. However, in comparison to Sn spot, a number of large platinum spot were observed, which is consistent with the results of the BET surface area measurements.

Figure 2 shows X-ray diffraction (XRD) patterns for the Pt-Sn/MWCNTs catalyst. A broad peak at $2 \Theta=$

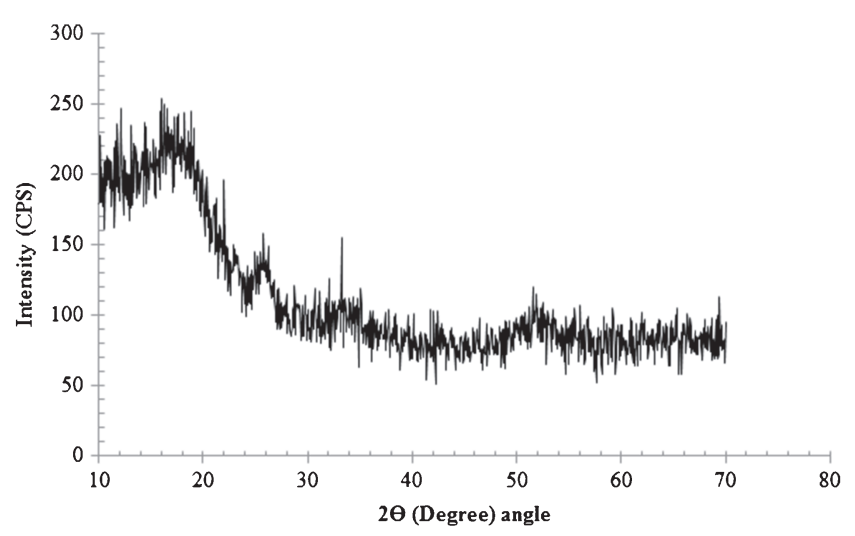

Figure 2. XRD of Pt-Sn/MWCNTs. $25^{\circ}$ for support material while peaks corresponding to tin oxide $\left(2 \Theta=34^{\circ}\right.$ and $\left.52^{\circ}\right)$ and $\left(2 \Theta=40^{\circ}\right.$ and $\left.47^{\circ}\right)$ for (fcc) structure of Pt were observed; no crystalline impurities were observed. The positions of the peaks, corresponding to $\mathrm{Sn}$ and $\mathrm{Pt}$ are in good agreement with literature. ${ }^{11}$

\subsection{Oxidation of cyclohexane}

The catalytic performance of Pt-Sn/MWCNTs catalyst for the selective oxidation of cyclohexane with molecular oxygen was investigated. The results obtained are given in table 2. Highly efficient oxidation of cyclohexane to KA-oil with remarkable conversion and selectivity was accomplished in the presence of the catalyst at $120^{\circ} \mathrm{C}$ for $6 \mathrm{~h}$ in oxygen atmosphere, without using radical initiators or radical scavengers.

Table 2 shows the results obtained by varying different reaction parameters. At a fixed temperature of $120^{\circ} \mathrm{C}$ and reaction duration of $6 \mathrm{~h}$, the conversion of 
Table 2. Performance of the catalyst at various reaction conditions.

\begin{tabular}{|c|c|c|c|c|c|c|c|c|}
\hline \multirow{2}{*}{$\begin{array}{l}\mathrm{O}_{2} \\
(\mathrm{MPa})\end{array}$} & \multirow{2}{*}{$\begin{array}{r}\text { Temp } \\
\left({ }^{\circ} \mathrm{C}\right)\end{array}$} & \multirow{2}{*}{$\begin{array}{l}\text { Time } \\
\text { (h) }\end{array}$} & \multirow{2}{*}{$\begin{array}{c}\text { Conv } \\
(\mathrm{mol} \%)\end{array}$} & \multirow{2}{*}{$\begin{array}{l}\text { KA-oil yield } \\
\left(10^{-2} \times \text { mol }\right)\end{array}$} & \multirow{2}{*}{$\begin{array}{c}\text { KA-oil syn rate } \\
\left(10^{-3} \times \mathrm{mol} \mathrm{g}^{-1} \mathrm{~h}^{-1}\right)\end{array}$} & \multicolumn{2}{|c|}{$\begin{array}{l}\text { Selectivity } \\
(\mathrm{mol} \%)\end{array}$} & \multirow{2}{*}{$\begin{array}{l}\text { TOF } \\
\left(\mathrm{h}^{-1}\right)\end{array}$} \\
\hline & & & & & & nol & none & \\
\hline 0.8 & 120 & 6 & 0 & 0 & 0 & 0 & 0 & 0 \\
\hline 1.0 & & & 13.2 & 1.27 & 4.23 & 56.6 & 29.4 & 1686.8 \\
\hline 1.2 & & & 19.7 & 1.89 & 6.32 & 55.3 & 29.3 & 2476.3 \\
\hline 1.5 & & & 24.1 & 2.32 & 7.70 & 55.2 & 28.2 & 2987.1 \\
\hline 1.8 & & & 25.3 & 2.43 & 8.12 & 51.3 & 27.8 & 2974.3 \\
\hline 2.0 & & & 25.8 & 2.48 & 8.28 & 40.0 & 24.0 & 2454 \\
\hline \multirow[t]{4}{*}{1.5} & 110 & 6 & 11.5 & 1.10 & 3.60 & 56.5 & 30.4 & 1485.4 \\
\hline & 120 & & 24.1 & 2.32 & 7.70 & 55.2 & 28.2 & 2987.1 \\
\hline & 130 & & 24.7 & 2.38 & 7.90 & 51.0 & 20.6 & 2628 \\
\hline & 140 & & 28.8 & 2.77 & 9.20 & 48.8 & 20.5 & 2554.3 \\
\hline \multirow[t]{5}{*}{1.5} & 120 & 1 & 0 & 0 & 0 & 0 & 0 & 0 \\
\hline & & 3 & 11.1 & 1.06 & 7.10 & 54.1 & 31.5 & 1383.6 \\
\hline & & 6 & 24.1 & 2.32 & 7.70 & 55.2 & 28.2 & 2987.1 \\
\hline & & 9 & 24.5 & 2.36 & 5.20 & 39.1 & 23.4 & 2065 \\
\hline & & 12 & 25.5 & 2.45 & 4.00 & 35.6 & 19.6 & 1424 \\
\hline
\end{tabular}

cyclohexane improved with a rise in the pressure of oxygen; the highest selectivity was achieved at $1.5 \mathrm{MPa}$ pressure of oxygen. However, the selectivity decreased as the pressure was increased, because it favors an overoxidation of cyclohexane into by-products such as pentanoic acid, glutaric acid and carbon dioxide. It can be seen from table 2 that while the reaction duration and the pressure of oxygen were kept constant, the conversion ratio peaked at $120^{\circ} \mathrm{C}$ and was virtually constant at higher temperatures. However, the total selectivity for KA-oil decreased with increasing temperature. It is also evident from table 2, that at a constant temperature and pressure of oxygen, the oxidation of cyclohexane occurs in 3-12 h. The reaction does not appear to slow down with time, which indicates that there is no loss of catalytic activity over time. However, the selectivity for KA-oil decreases with increasing reaction time as it gives way to over-oxidation of cyclohexane.

Figure 3 presents the relationship between the cyclohexane conversion ratio and the selectivity for KAoil under various reaction conditions for all the catalysts involved in the study. The selectivity for KA-oil decreases very gradually with increasing cyclohexane conversion ratio until it a cyclohexanol conversion ratio of $24.1 \%$ is reached. However, when the conversion ratio of $24.1 \%$ is exceeded, the selectivity decreases sharply due to over-oxidation. Therefore, it is crucial to limit the conversion ratio to just below this threshold in order to satisfy the requirements for both high conversion ratio and selectivity. Based on the observations, the optimal conditions for the oxidation of cyclohexane to KA oil with Pt-Sn/MWCNTs are $120^{\circ} \mathrm{C}, 1.5 \mathrm{MPa}$,

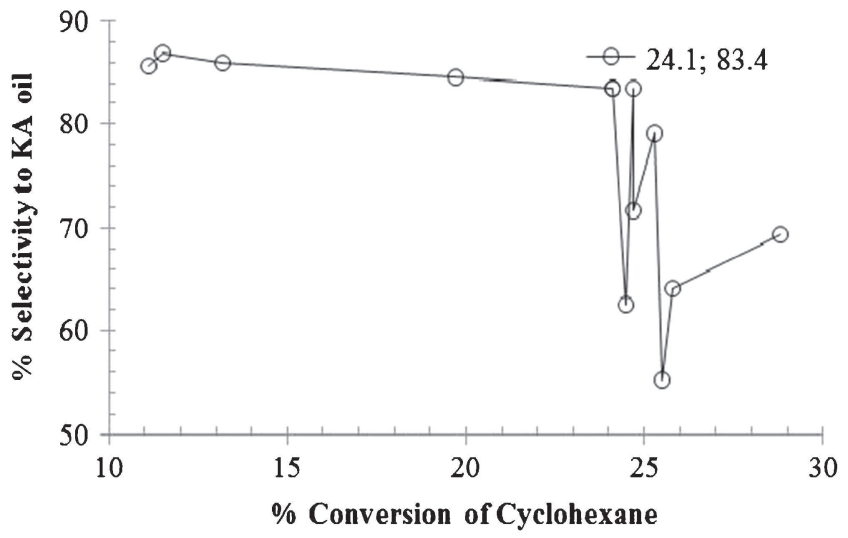

Figure 3. Plot for optimal reaction conditions; Conversion ratio and selectivity of cyclohexane to KA oil. Reaction conditions: $50 \mathrm{mg}$ catalyst, $10 \mathrm{~mL}$ cyclohexane, Temperature; $110-140^{\circ} \mathrm{C}$, Reaction duration; 3-12h.

oxygen and $6 \mathrm{~h}$ reaction duration. The optimal conditions provide $24.1 \%$ cyclohexane conversion ratio and $83.4 \%$ selectivity for KA oil. Furthermore, the catalyst was found to be stable and did not develop any change in its activity and selectivity, after five runs of the catalytic test.

The cyclohexane oxidation reaction proceeds via the free radical chain mechanism as shown in the schemes $1-5 .{ }^{12-14}$

The chain reaction is initiated by hemolytic bond cleavage of the cyclohexyl hydroperoxide $(\mathrm{CyOOH})$, according to reaction (1). Tin ions can exhibit redox activity between $\mathrm{Sn}^{2+}$ and $\mathrm{Sn}^{4+}$, the entire cycle produce 2 electrons within the closed loop oxygen from air (scheme 6). 
$\longrightarrow \mathrm{HO}^{\circ}+$<smiles>OC1C[CH+]CCC1C1CCCCC1</smiles>
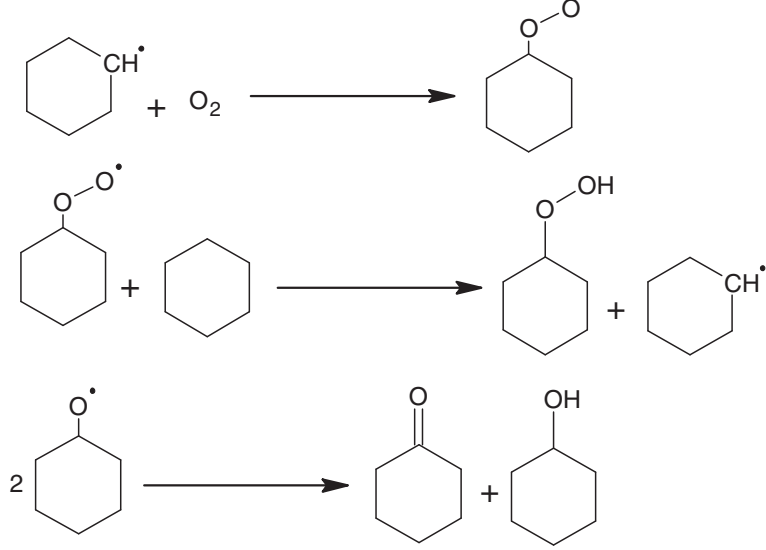

Scheme 1-5. Free radical chain mechanism of cyclohexane oxidation.

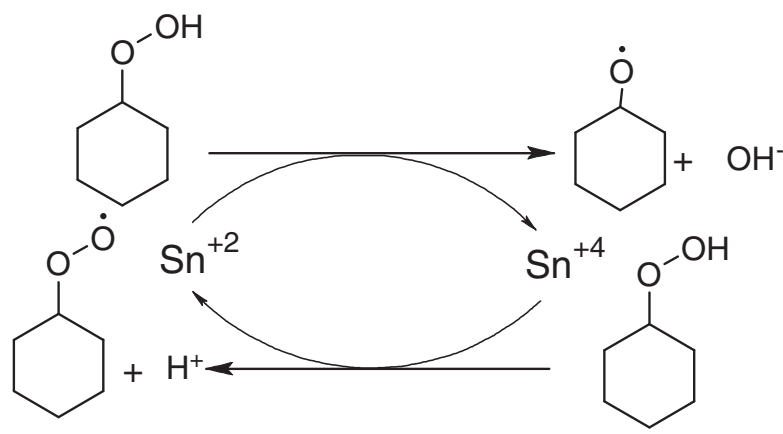

$(6$

Scheme 6. Tin catalyzed decomposition of cyclohexyl hydroperoxide.

The $\mathrm{CyO}$ radical produced by reaction (1) reacts with cyclohexane according to (2) to form the cyclohexyl radical $\left(\mathrm{Cy}^{\prime}\right)$. This then rapidly reacts with molecular $\mathrm{O}_{2}$ to form the cyclohexyl peroxy radical (CyOO ) according to reaction (3). The $\mathrm{Cy}$ radical is continuously regenerated in reaction (4). The formation of $\mathrm{CyOH}$ and $\mathrm{Cy}=\mathrm{O}$ has been attributed to chain termination by mutual destruction of two $\mathrm{CyOO}$ radicals according to reaction (5). ${ }^{12-14}$ The selectivity of $\mathrm{CyOOH}$ typically decreases with increasing conversion ratio. ${ }^{15}$ Under the present reaction conditions, $\mathrm{CyOOH}$ was not detected in the products, because it decomposed into $\mathrm{Cy}=\mathrm{O}$ and $\mathrm{CyOH}$ by the radical chain reaction. However, in the reaction mechanism shown in (1) to (5), $\mathrm{CyOOH}$ must be produced as the starting material. Since the present process does not involve a radical initiator, $\mathrm{CyOOH}$ formation is the ratedetermining step. ${ }^{16}$ This oxidation reaction is facilitated by the readily reducible $\mathrm{Pt}-\mathrm{Sn} / \mathrm{MWCNTs}$, which can provide active oxygen species from the catalyst bulk. This oxygen then reacts with cyclohexane at the interface of the platinum and tin oxide phases. ${ }^{17}$ The PtSn/MWCNTs catalyst has a significantly high oxidation activity; hence, no radical initiator is required. However, at high cyclohexane conversion ratio, both $\mathrm{Cy}=\mathrm{O}$ and $\mathrm{CyOH}$ are further oxidized, and the selectivity for $\mathrm{Cy}=\mathrm{O}$ and $\mathrm{CyOH}$ are consequently reduced.

\section{Conclusions}

Pt-Sn/MWCNTs catalysts were synthesized and tested for the partial oxidation of cyclohexane into KA oil. The cyclohexane conversion ratio of $24.1 \%$ and selectivity of $83.4 \%$ for KA oil were successfully attained in $6 \mathrm{~h}$ at $1.5 \mathrm{MPa}$ pressure of oxygen and $120^{\circ} \mathrm{C}$. Optimal conditions for the partial oxidation of cyclohexane to KA oil are $1.5 \mathrm{MPa}$ pressure of oxygen, $120^{\circ} \mathrm{C}$ temperature and $6 \mathrm{~h}$ reaction time. Notably, the reaction did not require radical initiator or free radical scavenger. The pressure of oxygen required is also significantly lower than that typically applied in conventional reactions, due to the combination of catalytic oxidation by platinum, provision of oxygen from the bulk of the tin oxide promoter, and the adsorption of cyclohexane onto tin oxide. A remarkable advantage of the catalyst is that it can be used several times without any loss of activity and selectivity.

\section{Acknowledgements}

The authors greatly acknowledge the financial support of High Education Commission of Pakistan, Project No. 20-1897/NRPU/R\&D/HEC/116806, under National Research Program for Universities.

\section{References}

1. Musser M T 2012 Cyclohexanol and Cyclohexanone In Ullmann's Encyclopedia of Industrial Chemistry (Weinheim: Wiley-VCH)

2. Kokotailo G T, Lawton S L, Olson D H and Meier W 1978 Nature 27243

3. Kresge C T, Leonowicz M E, Roth W J, Vartuli J C and Beck J S 1992 Nature 359710

4. Zhao R, Ji D, Lv G, Qian G, Yan L, Wang X and Suo J 2004 Chem. Commun. 40904 
5. Wang C, Chen L and Qi Z 2013 Catal. Sci. Technol. 3 1123

6. Liu Y, Tsunoyama H, Akita T, Xie S and Tsukuda T 2011 ACS Catal 12

7. Maksimchuk N V, Kolvalenko K A, Fedin V P and Kholdeeva O A 2012 Chem. Commun. 486812

8. Yang X, Yu H, Peng F and Wang H 2012 ChemSusChem. 51213

9. Sadiq M, Alam S, Mabood F, Bangash F K and Ilyas M 2012 Tenside Surf. Det. 4932

10. Farghali A A, Bahgat M, Elrouby W M A and Khedr M H 2013 J. Nanostructure Chem. 350

11. Ayoub J M S, De Souza R F B, Silva J C M, Piasentin R M, Spinacé E V, Santos M C and Neto A O 2012 Int. J. Electrochem. Sci. 711351
12. Hereijgers B P C and Weckhuysen B M $2010 \mathrm{~J}$. Catal. 27016

13. Tolman C A, Druliner J D, Nappa M J and Herron N 1989 In Activation and Functionalization of Alkanes C. L. Hill (Ed.) (New York: Wiley)

14. Sheldon R A and Kochi J K 1981 In Metal-Catalyzed Oxidation of Organic Compounds (New York: Academic Press)

15. Lu G, Zhao R, Qian G, Qi Y, Wang X and Suo J 2004 Catal. Lett. 97115

16. Pohorecki R, Balyga J, Moniuk W, Podgorska W, Zdrojkowski A and Weirzchowski P T 2001 Chem. Eng. Sci. 561285

17. Yasuda K, Yoshimura A, Katsuma A, Masui T and Imanaka N 2012 Bull. Chem. Soc. Jpn. 85522 